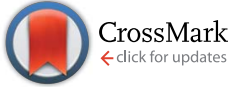

Cite this: RSC Adv., 2017, 7, 12041

Received 27th October 2016 Accepted 9th February 2017

DOI: 10.1039/c6ra25931f

rsc.li/rsc-advances

\section{Synthesis, characterization and performance of bifunctional catalysts for the synthesis of menthol from citronellal $\uparrow$}

\author{
J. ten Dam, ${ }^{a}$ A. Ramanathan, ${ }^{b}$ K. Djanashvili, ${ }^{a}$ F. Kapteijn ${ }^{c}$ and U. Hanefeld ${ }^{\star a}$ \\ The synthesis of a series of bifunctional catalysts (1 wt\% Pt/W-TUD-1 (Technische Universiteit Delft-1) and 1 \\ $\left.\mathrm{wt} \% \mathrm{Pt} / \mathrm{WO}_{3} / \mathrm{TUD}-1\right)$ with different tungsten loadings $(5-30 \mathrm{wt} \% \mathrm{WO}$ ) is described. They were \\ characterized using ICP-OES, INAA, $\mathrm{N}_{2}$ physisorption, XRD and TEM. Their catalytic performance (activity \\ and selectivity) was evaluated in the two-step catalytic synthesis of menthol from citronellal using kinetic \\ analysis. Introducing tungsten during the TUD-1 synthesis results in a high $\mathrm{WO}_{3}$ dispersion, essential for \\ the acidity of the catalyst. High tungsten dispersion is also critical for the Pt hydrogenation activity. \\ Therefore, high dispersion combined with optimal tungsten loading resulted in the highest catalytic \\ activity. The best performing catalyst was 1 wt\% Pt/W-TUD-1 (silicon to tungsten ratio of 30), with the \\ highest yields of menthol (96\%).
}

\section{Introduction}

Citronellal can be obtained from the fractional distillation of natural citronella oil. This monoterpenoid is a versatile building block for a series of organic syntheses. ${ }^{1}$ One extensively researched process, is the one pot, 2-step synthesis of menthol. ${ }^{2-7}$ This sequence relies on the acid catalysed Prins cyclisation that converts citronellal into isopulegol. ${ }^{8-12}$ This olefin is subsequently hydrogenated to form menthol. ${ }^{2-7}$

The process requires both an acid (Brønsted or Lewis acid) and a hydrogenation catalyst functionality. Bifunctional acidic hydrogenation catalysts can be obtained in various ways. They can be prepared by impregnating acidic supports/catalysts like zeolites, acidic carbons, Al-TUD-1, B-TUD-1, SAPOs and acidic resins with a hydrogenation metal precursor $(\mathrm{Pt}, \mathrm{Pd}, \mathrm{Rh}, \mathrm{Ru}, \mathrm{Ir}$, $\mathrm{Cu}, \mathrm{Ni}$ and $\mathrm{Co}) .^{2-5,13-16}$ The ratio of Lewis and Brønsted acid were varied to investigate their influence on the Prins cyclisation. Only in the case of $\mathrm{Zr}$ and $\mathrm{Al}$ in one material some synergy was displayed. ${ }^{13}$

Another option is to consecutively impregnate an inert carrier with an acid and a hydrogenation metal precursor solution (or vice versa). Ferrari et al. studied the influence of the order of impregnation on the activity of a CoMo catalyst in

${ }^{a}$ Biocatalysis and Organic Chemistry, Department of Biotechnology, Delft University of Technology, Van der Maasweg 9, 2629 HZ Delft, The Netherlands. E-mail: U. Hanefeld@tudelft.nl; Tel: +31 (0)15 2782683

${ }^{b}$ Center for Environmentally Beneficial Catalysis (CEBC), The University of Kansas, Lawrence, KS 66047, USA

${ }^{c}$ Catalysis Engineering, Department of Chemical Engineering, Delft University of Technology, Van der Maasweg 9, 2629 HZ Delft, The Netherlands

$\dagger$ Electronic supplementary information (ESI) available. See DOI: 10.1039/c6ra25931f a hydrodeoxygenation and decarboxylation. They showed that acid impregnation (Mo) followed by hydrogenation metal (Co) produced a more active catalyst. ${ }^{17}$

This paper describes the synthesis of two series of bifunctional acidic hydrogenation catalysts. The acidity is derived from tungsten, while platinum is the hydrogenation centre. ${ }^{18-21}$ The first series is based on the direct synthesis of W-TUD-1, which is subsequently impregnated with a platinum precursor solution. The second series is based on the consecutive impregnation of TUD-1 with $\mathrm{WO}_{3}$ and with platinum precursor solutions. Their catalytic activity is evaluated in the two-step synthesis of menthol from citronellal (Scheme 1). ${ }^{2-7}$ In this example the selectivity revolves around the acidic sites: they should be acidic enough to catalyse the Prins cyclisation of citronellal, but they should not be able to remove the formed hydroxyl group through elimination. ${ }^{8-12}$

TUD-1 was chosen as a support because of its amorphous structure and relatively large pore size. These characteristics aid in overcoming diffusion limitations, which is particularly important in liquid phase fine chemical synthesis because of the molecular sizes involved..$^{13,22-24}$ Previous work showed that direct synthesis of W-TUD-1 resulted in smaller $\mathrm{WO}_{3}$ particles (below XRD detection limit, i.e. 2-3 nm) leading to a more acidic

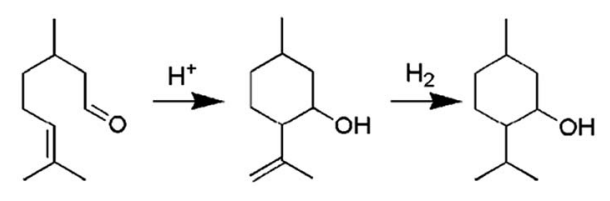

citronellal 1 isopulegol 2 menthol 3
Scheme 1 Menthol synthesis from citronellal. 
catalyst than the impregnation method $\left(\mathrm{WO}_{3} / \mathrm{TUD}-1\right){ }^{25} \mathrm{Pt}$ was chosen for its high hydrogenation activity.

The menthol synthesis from citronellal was chosen as model reaction to establish the catalytic activity and selectivity of the synthesized catalysts. The advantage of this model reaction is that both the acid and hydrogenation catalysis can be tested individually: the conversion of citronellal to isopulegol is acid catalysed and hydrogenation of isopulegol yields menthol..$^{2-12}$

\section{Experimental}

\section{Materials}

Tetraethoxysilane (TEOS, Aldrich, 98\%), triethanolamine (TEA, Acros, 97\%), tetraethylammonium hydroxide (TEAOH, Aldrich, $35 \mathrm{wt} \%$ aqueous solution), tungstic acid (Aldrich, >99\%), ammonium hydroxide (J. T. Baker, $25 \mathrm{wt} \%$ aqueous solution), tungsten(vi) ethoxide (Alfa Aesar), dry ethanol (Merck), dry ipropanol (Merck), chloroplatinic acid $\left(\mathrm{H}_{2} \mathrm{PtCl}_{6} \cdot 6 \mathrm{H}_{2} \mathrm{O}\right.$, Aldrich, $\geq 37.50 \%$ Pt basis), isopulegol (Acros, technical), (rac)-citronellal (Acros, $\geq 95 \%$ ), dry toluene (sure seal, Aldrich), trimethylbenzene (Acros, 99\%).

\section{Catalyst preparation}

WO $_{3}$ /TUD-1. TUD-1 was synthesized according to Heikkila et al. ${ }^{26}$ using $20.0 \mathrm{~g}$ tetraethoxysilane (TEOS, Aldrich, 98\%), $14.8 \mathrm{~g}$ triethanolamine (TEA, Acros, 97\%), $5.1 \mathrm{~g}$ demineralized $\mathrm{H}_{2} \mathrm{O}$ and $20.1 \mathrm{~g}$ tetraethylammonium hydroxide (TEAOH, Aldrich, 35 wt\% aqueous solution). The final molar gel composition was $\mathrm{SiO}_{2} / \mathrm{TEA} / \mathrm{H}_{2} \mathrm{O} / \mathrm{TEAOH}=1: 1: 11: 0.5$. Three samples of $\mathrm{WO}_{3} /$ TUD-1 $(5,10$ and $20 \mathrm{wt} \%)$ were prepared by incipient wetness impregnation of TUD-1 (pore volume $=0.897$ $\mathrm{cm}^{3} \mathrm{~g}^{-1}$ ) using solutions of appropriate amounts of tungstic acid (Aldrich) in aqueous ammonium hydroxide (J. T. Baker, 25 $w t \%$ aqueous solution). The material was dried overnight at $95^{\circ} \mathrm{C}$ and calcined at $600^{\circ} \mathrm{C}$ for $10 \mathrm{~h}$ with a temperature ramp of $1{ }^{\circ} \mathrm{C} \mathrm{min}^{-1}$ in a flow of dry air. These materials are denoted by $\mathrm{WO}_{3} / \mathrm{TUD}-1_{x}$, where $x(5,10$ or 20$)$ represents the $\mathrm{wt} \%$ of $\mathrm{WO}_{3}$ on the TUD-1 support.

Pt/WO $/ \mathbf{W O}_{3}$ /TUD-1. $\mathrm{WO}_{3} /$ TUD- $\mathbf{1}_{x}$ samples $(5,10$ and $20 \mathrm{wt} \%)$ were synthesized as described above. The incorporation of 1 wt $\%$ platinum was performed by incipient wetness impregnation (pore volume determined by nitrogen physisorption) using solutions containing appropriate amounts of aqueous chloroplatinic hexahydrate $\left(\mathrm{H}_{2} \mathrm{PtCl}_{6} \cdot 6 \mathrm{H}_{2} \mathrm{O}\right.$, Aldrich, $\geq 37.50 \mathrm{wt} \% \mathrm{Pt}$ basis). The material was dried overnight at $95{ }^{\circ} \mathrm{C}$ and calcined at $600{ }^{\circ} \mathrm{C}$ for $2 \mathrm{~h}$ with a heating rate of $1^{\circ} \mathrm{C} \mathrm{min}^{-1}$ in a flow of dry air. These materials were then stored in a drying oven at $80^{\circ} \mathrm{C}$ to prevent water adsorption from air, thereby avoiding potential sintering upon recalcination. Catalysts are not specifically prereduced before reaction, but $\mathrm{PtO}_{x}$ is readily reduced at reaction conditions ( 20 bar hydrogen pressure and $80{ }^{\circ} \mathrm{C}$ ). These materials are denoted by $\mathrm{Pt} / \mathrm{WO}_{3} / \mathrm{TUD}-1_{x}$ where $x(5,10$ or 20$)$ represents the $\mathrm{wt} \%$ of $\mathrm{WO}_{3}$ on the TUD-1 support.

W-TUD-1. A series of W-TUD-1 ( $\mathrm{Si} / \mathrm{W}=50,40,30,20$ and 10) was synthesized using tungsten(vi) ethoxide $\left(\mathrm{W}(\mathrm{OEt})_{6}\right.$, Alfa Aesar) as tungsten precursor. Initially, tungsten(VI) ethoxide was dissolved in a mixture of TEA, dry ethanol $(8.0 \mathrm{~g})$ and dry ipropanol $(8.0 \mathrm{~g})$ in a $250 \mathrm{~mL}$ polyethylene bottle. Under vigorous stirring $20.0 \mathrm{~g}$ TEOS (Aldrich, 98\%) was slowly added with a dropping funnel. After stirring for $2-3 \mathrm{~h}$ a solution of TEAOH (20.1 g, Aldrich, $35 \mathrm{wt} \%$ aqueous solution) with additional demineralized $\mathrm{H}_{2} \mathrm{O}$ was added dropwise and the vigorous stirring was continued for another 1-2 $\mathrm{h}$. The amounts of $\mathrm{W}(\mathrm{OEt})_{6}$, TEA and demineralized $\mathrm{H}_{2} \mathrm{O}$ were chosen so that the final molar gel composition was $\mathrm{Si} / \mathrm{W} / \mathrm{TEA} / \mathrm{H}_{2} \mathrm{O} / \mathrm{TEAOH}=$ $1: n: 1+2 n: 11: 0.5$. The resulting liquid was poured into a porcelain dish and aged at room temperature for at least $24 \mathrm{~h}$. The resulting thickened gel was dried in an oven at $98{ }^{\circ} \mathrm{C}$ for at least $12 \mathrm{~h}$. The dried sample was ground and hydrothermally treated at $180{ }^{\circ} \mathrm{C}$ for $5 \mathrm{~h}$ in a stainless steel Teflon-lined autoclave. Finally, calcination was performed at $600{ }^{\circ} \mathrm{C}$ for $10 \mathrm{~h}$ with a heating rate of $1{ }^{\circ} \mathrm{C} \mathrm{min}{ }^{-1}$ in a flow of dry air. These materials are denoted by W-TUD- $1_{x}$, where $x(28,16,11,9$ or 7$)$ represents the $\mathrm{WO}_{3}$-loading in wt\%, which is equivalent to the following $\mathrm{Si} /$ $\mathrm{W}$ ratios, respectively: $10,20,30,40$ or 50 .

Pt/W-TUD-1. W-TUD-1 samples ( $\mathrm{Si} / \mathrm{W}=50,40,30,20$ and 10) were synthesized as described above. The incorporation of 1 $\mathrm{wt} \%$ platinum was performed by incipient wetness impregnation (pore volume determined by nitrogen physisorption) using solutions containing appropriate amounts of aqueous chloroplatinic hexahydrate $\left(\mathrm{H}_{2} \mathrm{PtCl}_{6} \cdot 6 \mathrm{H}_{2} \mathrm{O}\right.$, Aldrich, $\geq 37.50 \mathrm{wt} \% \mathrm{Pt}$ basis). The impregnated material was dried overnight at $95{ }^{\circ} \mathrm{C}$ and calcined at $600{ }^{\circ} \mathrm{C}$ for $2 \mathrm{~h}$ with a heating rate of $1^{\circ} \mathrm{C} \mathrm{min}{ }^{-1}$ in a flow of dry air. These materials were then stored in a drying oven at $80{ }^{\circ} \mathrm{C}$ to prevent water adsorption from air, thereby avoiding potential sintering upon recalcination. Catalysts are not specifically pre-reduced before reaction, but $\mathrm{PtO}_{x}$ is readily reduced at reaction conditions ( 20 bar hydrogen pressure and $\left.80{ }^{\circ} \mathrm{C}\right)$. These materials are denoted by Pt/W-TUD- $1_{x}$, where $x$ $(28,16,11,9$ or 7$)$ represents the $\mathrm{WO}_{3}$-loading in wt\%, which is equivalent to the following $\mathrm{Si} / \mathrm{W}$ ratios, respectively: 10, 20, 30, 40 or 50 .

\section{Catalyst characterization}

ICP-OES. Elemental analysis for Pt was performed using Inductively Coupled Plasma-Optical Emission Spectrometry ICP-OES (Optima 4300DV, Perkin Elmer USA). Samples were prepared by adding 5 to $10 \mathrm{mg}$ catalyst to $1 \mathrm{~mL}$ concentrated hydrochloric acid. This dispersion was left overnight and was then diluted using $50 \mathrm{~mL} 1.0 \%$ hydrofluoric and $1.5 \%$ sulfuric acid. Agitation for $24 \mathrm{~h}$ led to a homogenous solution.

INAA. Elemental analysis for Si and $\mathrm{W}$ was established by Instrumental Neutron Activation Analysis (INAA) and was performed at the Reactor Institute Delft (RID). The sample was irradiated with neutrons (neutron flux of $1.6 \times 10^{17}$ neutrons $\mathrm{s}^{-1} \mathrm{~cm}^{-2}$ ) in the Hoger Onderwijs Reactor, Delft. In this process, stable isotopes were converted into radioactive isotopes. These isotopes emit gamma radiation, which was measured with semi-conductor gamma-ray spectrometers equipped with a germanium semiconductor. The wavelength is specific for each element. The amount of this element was determined from the signal area of the sample and a calibration standard. 
$\mathbf{N}_{\mathbf{2}}$ physisorption. Specific surface areas and pore characteristics of the materials were determined using the BET and $\mathrm{BJH}$ models from nitrogen sorption measurements on a Quantachrome Autosorb-6B at $-196^{\circ} \mathrm{C}^{27}$ Prior to the measurements, the samples were degassed overnight under vacuum at $350{ }^{\circ} \mathrm{C}$ using a Quantachrome Autosorb degasser.

X-ray diffraction. X-ray diffraction patterns of the W-TUD-1 samples were recorded on a Bruker-AXS D8 Advance diffractometer with $\mathrm{Cu}-\mathrm{K} \alpha$ radiation, which was operated at $25 \mathrm{~mA}$ and 45 $\mathrm{kV}$. The measuring step size was $0.0387^{\circ}$ with a step time of $1 \mathrm{~s}^{-1}$. The diffraction spectrum was taken over a range from $5^{\circ}$ to $90^{\circ} 2 \theta$.

X-ray diffraction patterns of the $\mathrm{WO}_{3} / \mathrm{TUD}-1, \mathrm{Pt} / \mathrm{W}$-TUD-1 and $\mathrm{Pt} / \mathrm{WO}_{3} / \mathrm{TUD}-1$ samples were measured using a Bruker D8 Advance diffractometer with a Lynxeye detector and $\mathrm{Cu} \mathrm{K} \alpha$ radiation. Measuring range from $5^{\circ}$ to $95^{\circ} 2 \theta$ with a step size of $0.02^{\circ}$ and a scan speed of $0.15 \mathrm{~s}^{-1}$.

Electron microscopy. High-resolution transmission electron microscopy (HR-TEM) was performed on a Philips CM30UT electron microscope with a LaB6 filament as the source of electrons operated at $300 \mathrm{kV}$. Samples were prepared by placing a few droplets of a suspension of ground sample in ethanol on the grid, followed by drying at ambient conditions.

$\mathbf{N H}_{3}$-temperature programmed desorption. A calcined sample was pretreated in a continuous stream of $\mathrm{He}(10 \mathrm{~mL}$ $\mathrm{min}^{-1}$ ) at $250{ }^{\circ} \mathrm{C}$ (ramping at $10{ }^{\circ} \mathrm{C} \mathrm{min}^{-1}$ from room temperature). After returning to $100{ }^{\circ} \mathrm{C}$, the sample was flushed for 30 min with ammonia $(9.982 \mathrm{~mol} \%$ ammonia in $\mathrm{He}, 10 \mathrm{~mL}$ $\min ^{-1}$ ). Subsequently the physically adsorbed ammonia was removed by flushing with $\mathrm{He}\left(10 \mathrm{~mL} \mathrm{~min}{ }^{-1}\right)$ for $30 \mathrm{~min}$ at the same temperature. Subsequently the temperature was ramped $\left(1{ }^{\circ} \mathrm{C} \mathrm{min}{ }^{-1}\right)$ from $100{ }^{\circ} \mathrm{C}$ to $600{ }^{\circ} \mathrm{C}$ and ammonia desorption was recorded on a Micromeritics Autochem 2910 equipped with a Thermal Conductivity Detector.

\section{Catalytic performance testing}

Isopulegol hydrogenation. Isopulegol hydrogenation was performed in a PolyBLOCK 8 (HEL group), a parallel autoclave reactor system consisting of eight $16 \mathrm{~mL}$ vessels. Technical isopulegol $(308.5 \mathrm{mg}, 2.0 \mathrm{mmol})$, dry toluene $(4.0 \mathrm{~mL})$ and catalyst (powder, $50 \mathrm{mg}$ ) were added to the reactor. The autoclave was purged three times with nitrogen $(20 \mathrm{bar})$ and three times with hydrogen $(20$ bar) and then pressurized with hydrogen $(20$ bar). The reactor was magnetically stirred $(800$ $\mathrm{rpm}$ ) and heated to $80{ }^{\circ} \mathrm{C}$ within 10 minutes and kept at this temperature for $16 \mathrm{~h}$. Stirring was stopped and the reactors were allowed to cool down to room temperature. 1,3,5-Trimethylbenzene ( $100 \mu \mathrm{L}, 0.716 \mathrm{mmol})$ was added to the reaction mixture as internal standard. A GC sample was prepared by diluting $40 \mu \mathrm{L}$ reaction mixture with $960 \mu \mathrm{L}$ dry toluene.

The apparent turnover frequency $\left(\mathrm{TOF}_{\mathrm{Pt}}\right)$ for hydrogenation is defined as mmol isopulegol converted per mol Pt per hour, based on a rate constant $k$ that is derived from a first order rate approximation (Appendix A).

Isopulegol hydrogenation - kinetic profile. A kinetic profile was obtained by using the isopulegol hydrogenation procedure that is described above by operating 8 parallel reactions in the
Table 1 Chemical composition and pore structure

\begin{tabular}{|c|c|c|c|c|c|}
\hline Catalyst & $\begin{array}{l}\mathrm{WO}_{3}, \\
\mathrm{wt} \%\end{array}$ & $\begin{array}{l}\text { Pt (ICP), } \\
\text { wt } \%\end{array}$ & $\begin{array}{l}S_{\mathrm{BET}}, \\
\mathrm{m}^{2} \mathrm{~g}^{-1}\end{array}$ & $\begin{array}{l}V_{\text {pore }} \\
\mathrm{cm}^{3} \mathrm{~g}^{-1}\end{array}$ & $\begin{array}{l}D_{\text {pore }}, \\
\AA\end{array}$ \\
\hline TUD-1 & - & - & 655 & 0.58 & 35 \\
\hline $\mathrm{WO}_{3} / \mathrm{TUD}-1_{20}$ & $18.2^{a}$ & - & 210 & 0.33 & 60 \\
\hline $\mathrm{WO}_{3} /$ TUD- $1_{10}$ & $8.8^{a}$ & - & 225 & 0.36 & 65 \\
\hline $\mathrm{WO}_{3} / \mathrm{TUD} \mathbf{1}_{5}$ & $5.3^{c}$ & - & 245 & 0.42 & 70 \\
\hline W-TUD-1 $1_{28}$ & $31.0^{a}$ & - & 420 & 0.48 & 45 \\
\hline W-TUD- $1_{16}$ & $17.0^{a}$ & - & 635 & 0.83 & 50 \\
\hline W-TUD- $1_{11}$ & $12.3^{a}$ & - & 710 & 0.81 & 45 \\
\hline W-TUD-1 19 & $9.6^{a}$ & - & 635 & 0.90 & 55 \\
\hline W-TUD-1 & $8.1^{a}$ & - & 720 & 0.91 & 50 \\
\hline $\mathrm{Pt} / \mathrm{WO}_{3} / \mathrm{TUD}-1_{20}$ & $14.3^{b}$ & 1.01 & 220 & 0.33 & 60 \\
\hline $\mathrm{Pt} / \mathrm{WO}_{3} / \mathrm{TUD}-1_{10}$ & $10.6^{b}$ & 1.01 & 200 & 0.33 & 65 \\
\hline $\mathrm{Pt} / \mathrm{WO}_{3} / \mathrm{TUD}-1_{5}$ & $5.3^{b}$ & 0.84 & 255 & 0.44 & 70 \\
\hline Pt/W-TUD-1 ${ }_{28}$ & $17.0^{b}$ & 1.06 & 415 & 0.49 & 50 \\
\hline Pt/W-TUD-1 16 & $13.8^{b}$ & 0.89 & 605 & 0.72 & 45 \\
\hline $\mathrm{Pt} / \mathrm{W}-\mathrm{TUD}-\mathrm{1}_{11}$ & $10.6^{b}$ & 0.72 & 655 & 0.72 & 45 \\
\hline Pt/W-TUD-1 $1_{9}$ & $9.4^{b}$ & 0.74 & 590 & 0.84 & 55 \\
\hline Pt/W-TUD-1 & $7.5^{b}$ & 0.61 & 670 & 0.74 & 45 \\
\hline
\end{tabular}
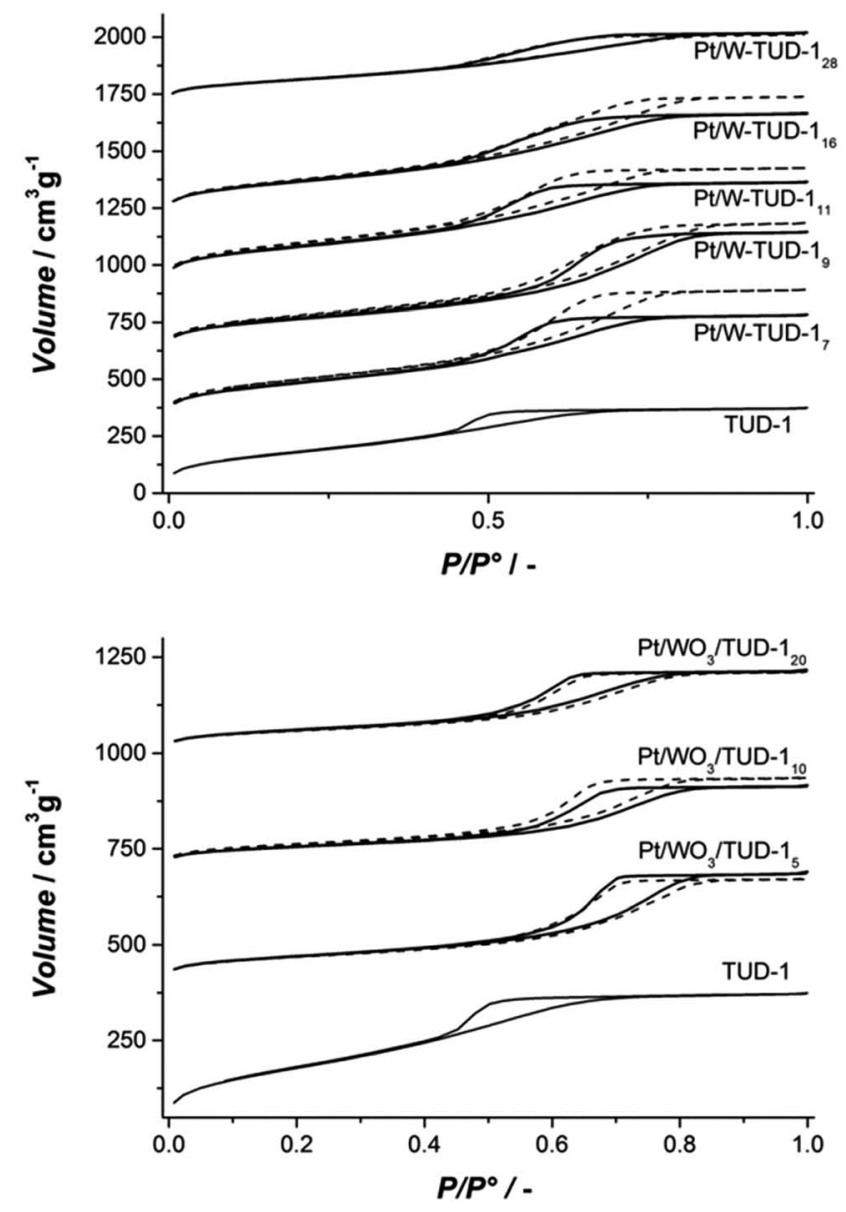

Fig. 1 (Top) isotherms of Pt/W-TUD-1 samples (bold) and W-TUD-1 samples (dashed); (bottom) isotherms of $\mathrm{Pt} / \mathrm{WO}_{3} / \mathrm{TUD}-1$ samples (bold) and $\mathrm{WO}_{3} / T U D-1$ samples (dashed). 
PolyBLOCK 8. Pt/W-TUD-1 11 (50 mg) was used as a catalyst and the reactions were individually stopped at the indicated reaction times.

Menthol synthesis. Menthol synthesis was performed in two stages in a PolyBLOCK 8. In the first stage (rac)-citronellal (308.5 $\mathrm{mg}, 2.0 \mathrm{mmol}$ ), dry toluene $(4.0 \mathrm{~mL}$ ) and catalyst (powder, $50 \mathrm{mg}$ ) were added to the reactor. The autoclave was purged three times with nitrogen (20 bar) and then pressurized with nitrogen (20 bar). The reactor was magnetically stirred (800 $\mathrm{rpm}$ ) and heated to $80{ }^{\circ} \mathrm{C}$ within 10 minutes and kept at this temperature for $5 \mathrm{~h}$. Stirring was stopped and the reactors were allowed to cool down to room temperature. A GC sample was prepared by diluting $40 \mu \mathrm{L}$ reaction mixture with $960 \mu \mathrm{L}$ dry toluene and 1,3,5-trimethylbenzene $(1.0 \mu \mathrm{L}, 7.16 \mu \mathrm{mol})$ was added to the GC sample as an internal standard.

The apparent turnover frequency $\left(\mathrm{TOF}_{\mathrm{w}}\right)$ for the Prins cyclisation is defined as mmol citronellal converted per mol $\mathrm{W}$ per hour, based on a rate constant $k$ that is derived from a first order rate approximation (Appendix A).

For stage 2 the reactor was closed again and the same procedure as described for isopulegol hydrogenation was followed.
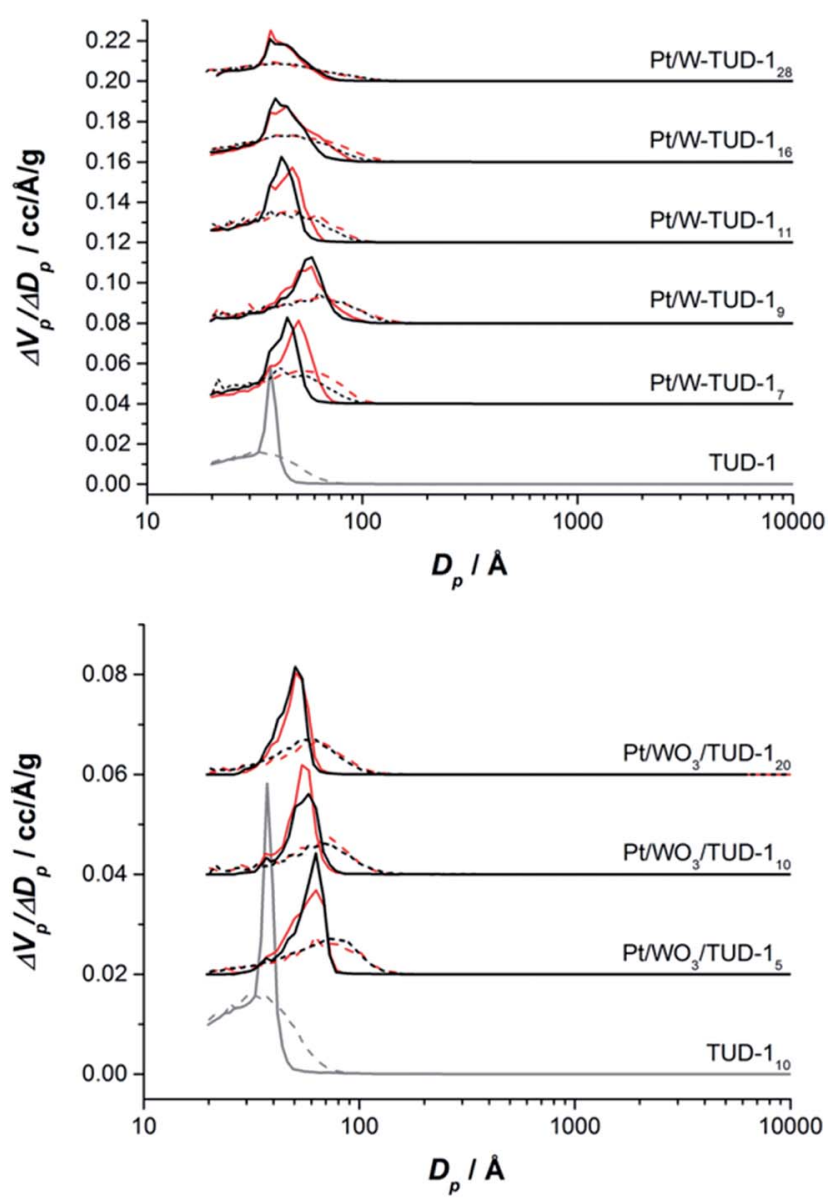

Fig. 2 Pore size distribution of Pt/W-TUD-1 samples (top). (Dashed) adsorption (solid) desorption. Red lines are samples without Pt. Pore size distribution of Pt/WO $/$ TUD-1 samples (bottom). (Dash) adsorption (solid) desorption. Red lines are samples without Pt. (distribution of different samples shifted by +0.02 units).
Recycling experiment. After the menthol synthesis the reaction mixture was filtered off and the catalyst was rinsed using dry toluene. Then ( $r a c)$-citronellal $(308.5,2.0 \mathrm{mmol}$ ) and dry toluene $(4.0 \mathrm{~mL})$ were added and the reaction procedure for menthol synthesis was repeated.

GC analysis. The GC samples were analyzed on a Shimadzu GC-17A gas chromatograph $\left(16 \mathrm{~min}\right.$ at $140{ }^{\circ} \mathrm{C}$ isothermal, followed by a ramp of $50{ }^{\circ} \mathrm{C} \min ^{-1}$ to $250{ }^{\circ} \mathrm{C}$, and $1 \mathrm{~min}$ isothermal) equipped with an injector at $250{ }^{\circ} \mathrm{C}$, a Cyclodex-B column $(60 \mathrm{~m} \times 0.25 \mathrm{~mm} \times 0.25 \mu \mathrm{m})$ and using a FID detector at $270{ }^{\circ} \mathrm{C}$. The retention times observed are: $8.0 \mathrm{~min}$ 1,3,5-trimethylbenzene, 13.4 and $13.5 \mathrm{~min}$ ( $\mathrm{rac}$ )-citronellal, 14.8, 15.0, 15.1, 15.2, 16.4 and $16.6 \mathrm{~min}$ ( $\mathrm{rac}$ )-isopulegol, 16.3, 16.3, 16.8 and $16.8 \mathrm{~min}$ ( $\mathrm{rac}$ )-menthol, 12.0 and $16.6 \mathrm{~min} 3,7-$ dimethyloctan-1-ol, 17.7 min 3,7-dimethyl-6-octen-1-ol., ${ }^{9,11,22}$ The Prins cyclisation of citronellal in this study is not stereoselective due to the relatively large pores of TUD-1 and forms a thermodynamic distribution of isomers. ${ }^{13,22}$ Moreover, this study utilizes ( $\mathrm{rac}$ )-citronellal and was therefore not focused on stereoisomeric distribution of reaction products.
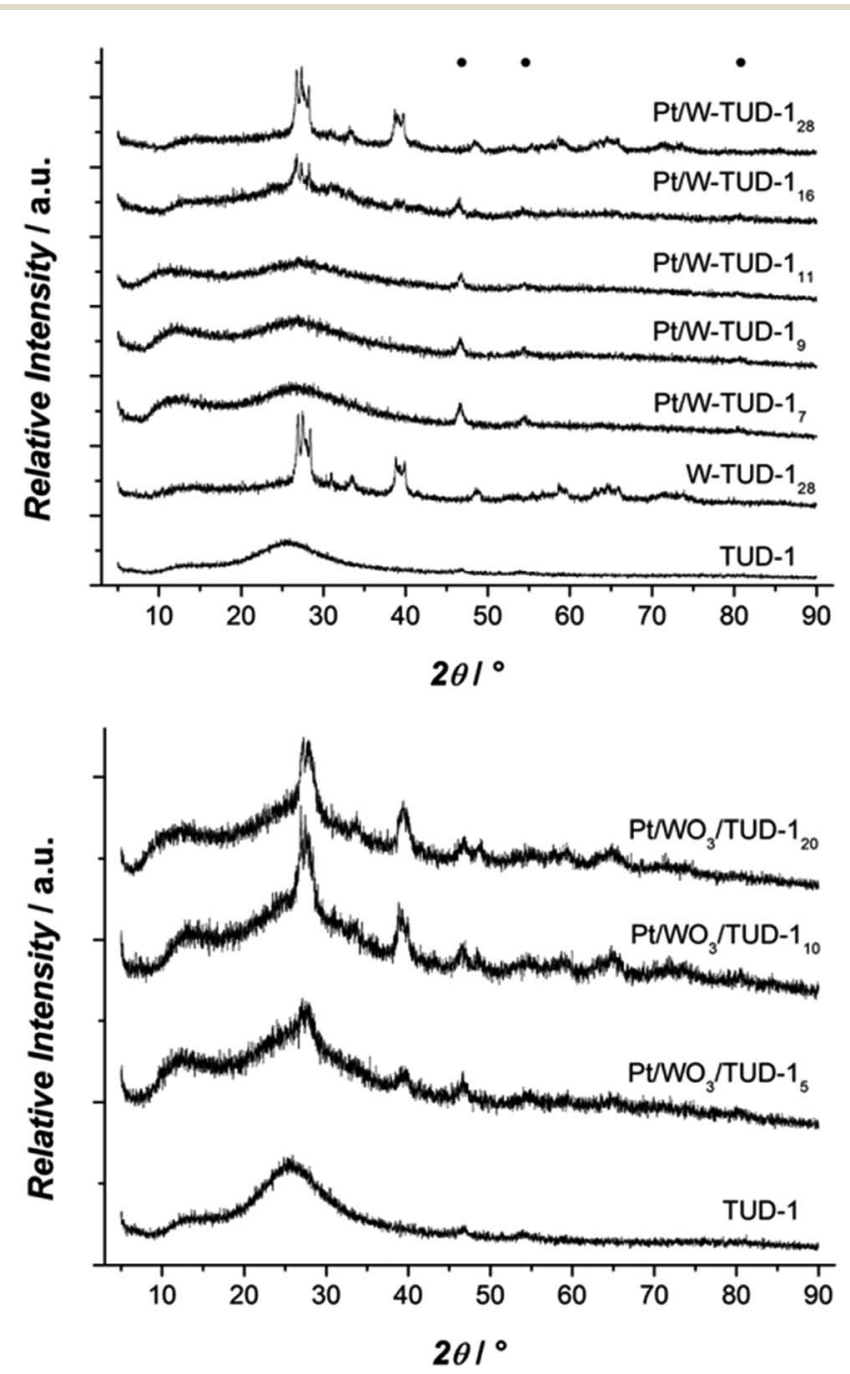

Fig. 3 XRD patterns of Pt/W-TUD-1 samples (top); XRD patterns of Pt/ $\mathrm{WO}_{3} / \mathrm{TUD}-1$ samples (bottom). 


\section{Results and discussion}

\section{Catalysts characterization}

The chemical composition of the samples is determined by a combination of INAA and ICP-OES. It shows a good correlation between the amounts of tungsten and platinum $(0.9 \pm 0.2 \mathrm{wt} \%)$ used for the synthesis of the catalysts and the amounts that were present in the materials (Table 1).

The pore structures of the materials are summarized in Table 1 and the nitrogen isotherms and pore size distributions are presented in Fig. 1. All samples show a type IV isotherm, typical for mesoporous materials where capillary condensation in mesopores occurs in a relative pressure range of 0.4-0.8. All materials show a $\mathrm{H} 2$ type hysteresis loop (Fig. 1). ${ }^{28}$

The W-TUD-1 samples have a larger pore volume and larger BET area than the $\mathrm{WO}_{3}$ /TUD-1 samples. Impregnation of the $\mathrm{W}$ TUD-1 samples with platinum precursor resulted in slightly lower pore volumes and BET areas, while impregnation of the $\mathrm{WO}_{3} /$ TUD-1 samples did not affect the physical properties of this material (Table 1; Fig. 2). It is noted that in some cases the adsorption-desorption hysteresis closes at 0.42 relative pressure, which indicates the influence of the tensile strength effect, indicating that the distinct pore size visible for e.g. TUD-1 at $\sim 3-4 \mathrm{~nm}$ is an artefact of this phenomenon. ${ }^{29}$

The XRD results show that the tungsten is better dispersed on the Pt/W-TUD-1 samples. $\mathrm{WO}_{3}$ reflections start only appearing at Pt/W-TUD- $1_{16}$, whereas $\mathrm{WO}_{3}$ reflections are already visible in $\mathrm{Pt} / \mathrm{WO}_{3} / \mathrm{TUD}-\mathbf{1}_{5}$. Addition of Pt to both the W-TUD- 1 and the $\mathrm{WO}_{3} /$ TUD-1 materials results in barely visible Pt reflections around 45 and $55^{\circ}$, indicating that the Pt particles on the material are well dispersed and close to the detection limit of XRD (Fig. 3).

The TEM images before and after Pt addition show that the supports are not affected by the impregnation procedure (Fig. 4). Platinum has been well dispersed on the W-TUD- $1_{7}$ support and is present in $<25 \mathrm{~nm}$ particles. The $\mathrm{Pt} / \mathrm{WO}_{3} / \mathrm{TUD}-1_{10}$ material shows a typical Pt particle size of $10 \mathrm{~nm}$ diameter. Fig. 5 shows more detailed TEM images and EDX analyses of Pt loaded $\mathrm{WO}_{3}$ /TUD-1 samples, and shows the differences between $\mathrm{Pt}$ and $\mathrm{WO}_{3}$ particles. Pt particles are identified by an EDX signal at $2.0 \mathrm{keV}$ and can be recognized by their dark colour and sharp edges. ${ }^{30}$ The $\mathrm{WO}_{3}$ particles are identified by EDX through the $\mathrm{W}$ signal at $1.8 \mathrm{keV}$ and are generally more vague than the sharp outlined Pt particles.

The particles on $\mathrm{Pt} / \mathrm{WO}_{3} / \mathrm{TUD}-1_{5}$ that were assigned with an ' $\mathrm{a}$ ' in the top row of Fig. 5 were identified as $\mathrm{WO}_{3}$ particles by EDX. The Pt particles, which tend to be smaller than the $\mathrm{WO}_{3}$ particles, were tagged with a ' $b$ '.

The Pt particle in the middle image in the middle row of Fig. 5 can be clearly distinguished from the $\mathrm{WO}_{3}$ particle in the image on the right hand side.

The TEM images of $\mathrm{Pt} / \mathrm{WO}_{3} / \mathrm{TUD}-\mathrm{1}_{20}$ show relatively more agglomerations of $\mathrm{WO}_{3}$, as a result of the higher tungsten loading. The irregularly shaped forms ('a') were identified as $\mathrm{WO}_{3}$, while the sharp dark dot proved to be a Pt particle (' $b$ '), which shows that the tungsten loading has no effect on the Pt particle size or shape. All of the $\mathrm{Pt} / \mathrm{WO}_{3} / \mathrm{TUD}-1$ materials, irrespective of the tungsten loading, show relatively large
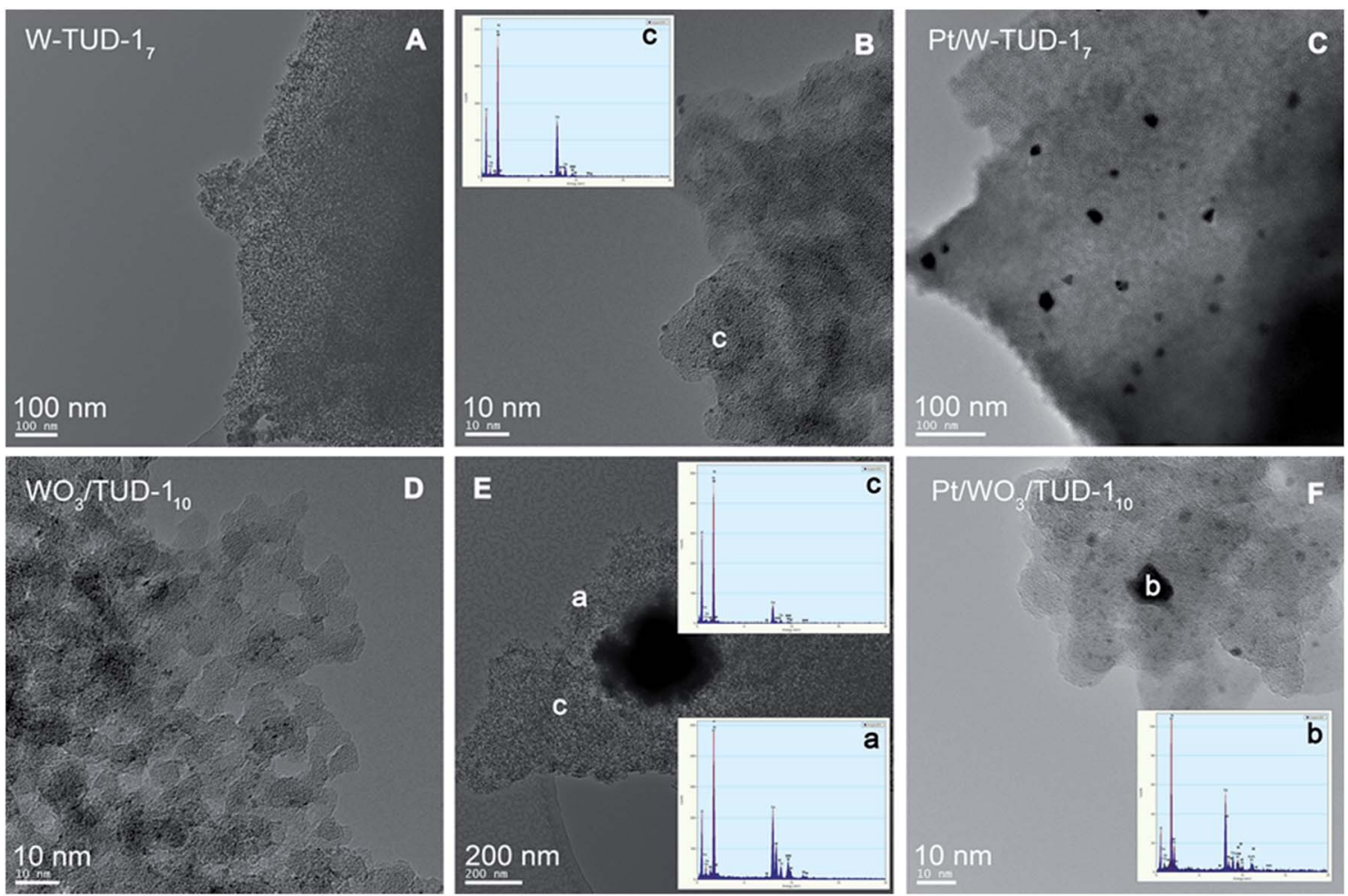

Fig. 4 TEM images of W-TUD-1 $1_{7}\left(A\right.$ and $B$ ) and Pt/W-TUD-1 $(C)$ and $W_{3} / T U D-1_{10}\left(D\right.$ and $E$ ) and Pt/WO $3 / T U D-1_{10}$ (F). 

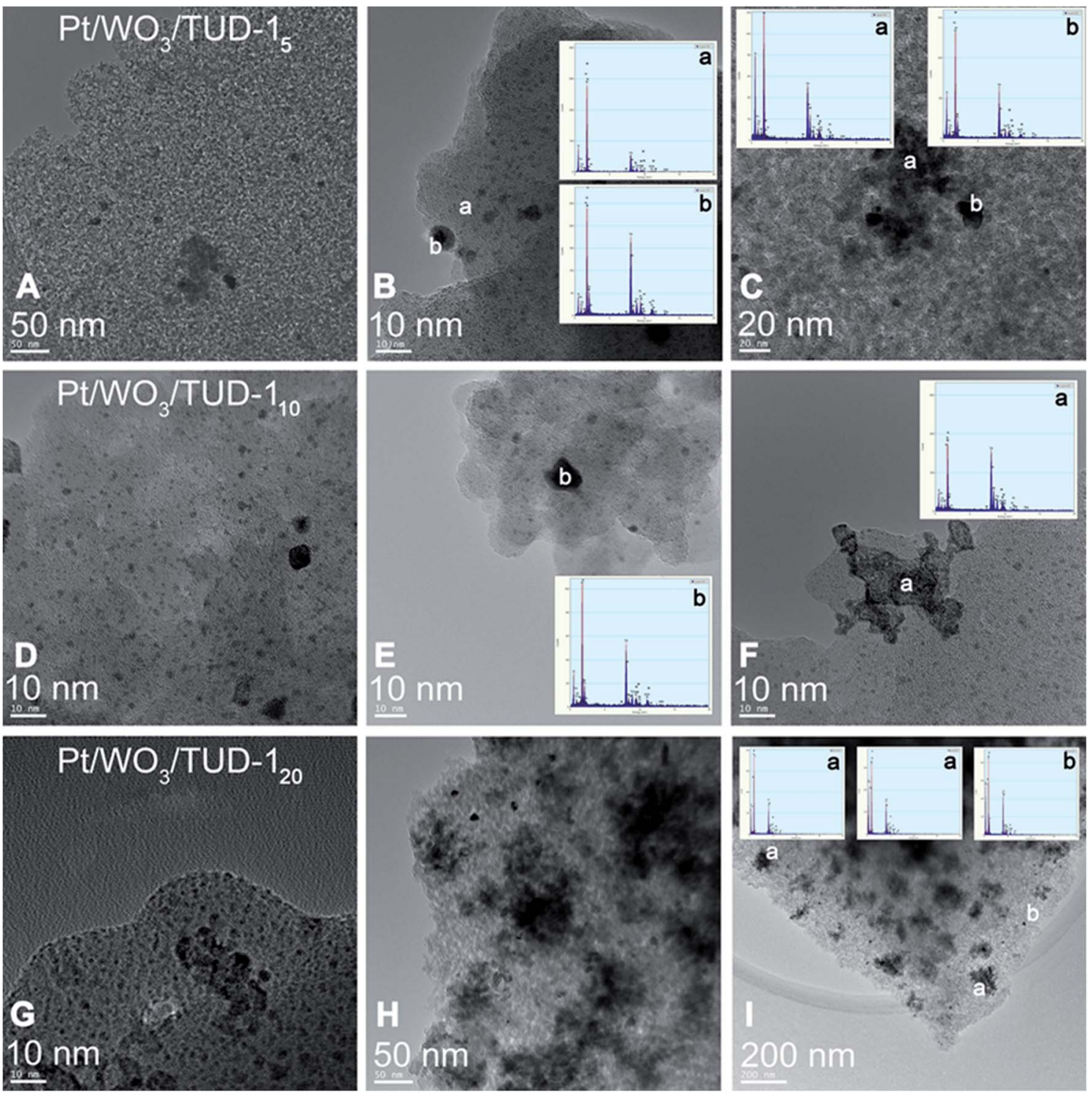

Fig. 5 TEM images of Pt impregnated $\mathrm{WO}_{3} / \mathrm{TUD}-1$ and corresponding EDX analysis. Pt/WO $3 / T U D-1_{5}(\mathrm{~A}-\mathrm{C})$; $\mathrm{Pt} / \mathrm{WO} \mathrm{O}_{3} / \mathrm{TUD}-\mathrm{1}_{10}$ (D-F); bottom: Pt/ $\mathrm{WO}_{3} / \mathrm{TUD}-1_{20}(\mathrm{G}-\mathrm{I})$.

agglomerates of $\mathrm{WO}_{3}$. The higher the tungsten loading, the larger these agglomerates become.

As a direct result of the high tungsten loading, the Pt/WTUD- $1_{28}$ material shows the largest $\mathrm{WO}_{3}$ agglomerations (Fig. 6, ' $a$ ') of all the Pt/W-TUD-1 samples. This is also recognized from the XRD results, which show a clear $\mathrm{WO}_{3}$ reflection for this material. Interestingly, there are not as much Pt particles (Fig. 6, 'b') visible on the Pt/W-TUD- $1_{28}$ (Fig. 6, $100 \mathrm{~nm}$ scale bar) as in the image of Pt/W-TUD- $1_{16}$ with the same scaling. On the other hand, the observed $\mathrm{WO}_{3}$ agglomerations in this image are much smaller than in the Pt/W-TUD- $1_{28}$ material and become scarce when the tungsten loading is lowered even further (Pt/W-TUD$1_{11}, 9$ and 7 ). The Pt particles on these materials do not seem to change much in size and shape over the range of tungsten loadings. Some EDX spectra of the TUD-1 background are added as comparison (Fig. 6, 'c').

\section{Catalyst performance}

Isopulegol hydrogenation. A hydrogenation rate constant $k$ was calculated for the conversion of isopulegol to menthol (Table 2), assuming a first order dependence on isopulegol concentration (vide infra). These rate constants are used to calculate initial rates $r_{0}$, which serve to compare the hydrogenation activity of the individual catalysts (Fig. 7). Both the Carberry number (extraparticle mass transfer) and the Weisz modulus (intraparticle mass transfer) proved to be sufficiently low to assure that the reactions proceeded without any mass transfer limitations (Appendix B). The different Pt loadings are taken into account by calculating a turnover frequency $\left(\mathrm{TOF}_{\mathrm{Pt}}\right)$, which is calculated by normalizing the initial rate for the Pt content (Table 2). The only observed trend is that the Pt/W-TUD1 catalysts are more active hydrogenation catalysts than the Pt/ $\mathrm{WO}_{3} /$ TUD-1 materials, with Pt/W-TUD- $1_{28}$ and Pt/W-TUD- $1_{9}$ 

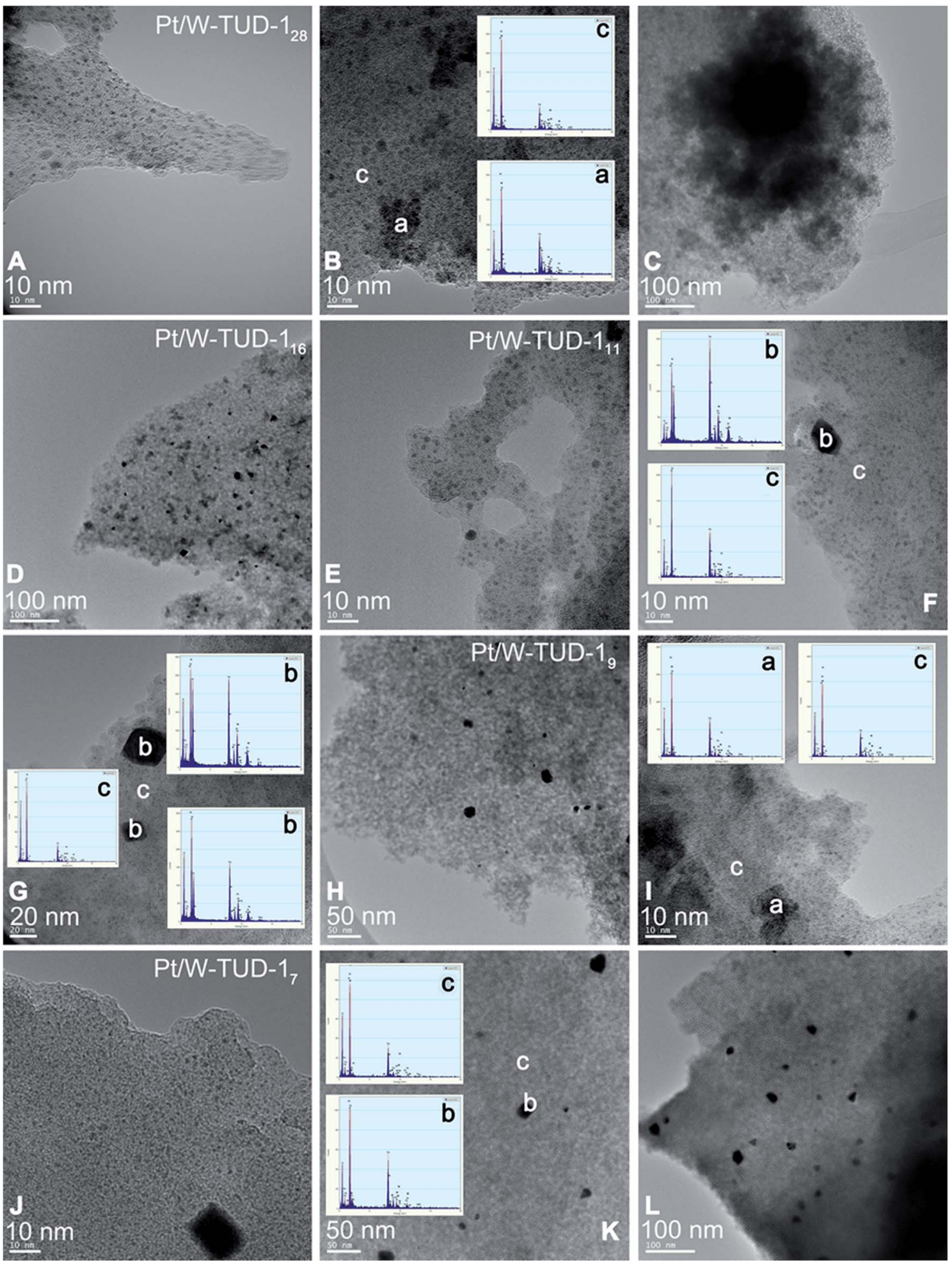

Fig. 6 TEM images of Pt impregnated W-TUD-1 and corresponding EDX analysis. Pt/W-TUD-1 $1_{28}(A-C) ; P t / W-T U D-1_{16}(D), P t / W-T U D-1_{11}(E-G)$; Pt/W-TUD-19 $(\mathrm{H}$ and I); Pt/W-TUD-1 $(\mathrm{J}-\mathrm{L})$.

being the most active in the series. However, there is no observable trend for the hydrogenation activity and the $\mathrm{WO}_{3}$ content of the catalysts themselves. This could indicate that the particle size of the $\mathrm{WO}_{3}$ that is present on the catalyst contributes to the hydrogenation activity.
It is important to note that $\mathrm{WO}_{3}$ by itself is not an active hydrogenation catalyst and the activity of the individual catalysts is likely to be dependent on the Pt metal surface and its environment. This relates to the Pt dispersion on the catalyst, but is difficult to quantify based on the XRD and TEM data. The 
Table 2 Conversion of isopulegol after $16 \mathrm{~h}$ hydrogenation over Pt/W-TUD-1 and Pt/WO $/$ TUD-1 catalysts and derived kinetic parameters. Reaction conditions: $2.0 \mathrm{mmol}$ isopulegol, $4.0 \mathrm{~mL}$ toluene, $50 \mathrm{mg}$ catalyst, $20 \mathrm{bar} \mathrm{H}_{2}, 80{ }^{\circ} \mathrm{C}, 800 \mathrm{rpm}$

\begin{tabular}{|c|c|c|c|c|c|}
\hline Pt/W-TUD-1 28 & 95.1 & 1.06 & 4.1 & 2.1 & 38 \\
\hline Pt/W-TUD-1 11 & 31.6 & 0.72 & 0.5 & 0.3 & 7.7 \\
\hline Pt/W-TUD-19 & 83.9 & 0.74 & 2.3 & 1.2 & 31 \\
\hline Pt/W-TUD-1 7 & 47.6 & 0.61 & 0.9 & 0.4 & 14 \\
\hline $\mathrm{Pt} / \mathrm{WO}_{3} / \mathrm{TUD}-1_{20}$ & 24.8 & 1.01 & 0.4 & 0.2 & 3.4 \\
\hline
\end{tabular}

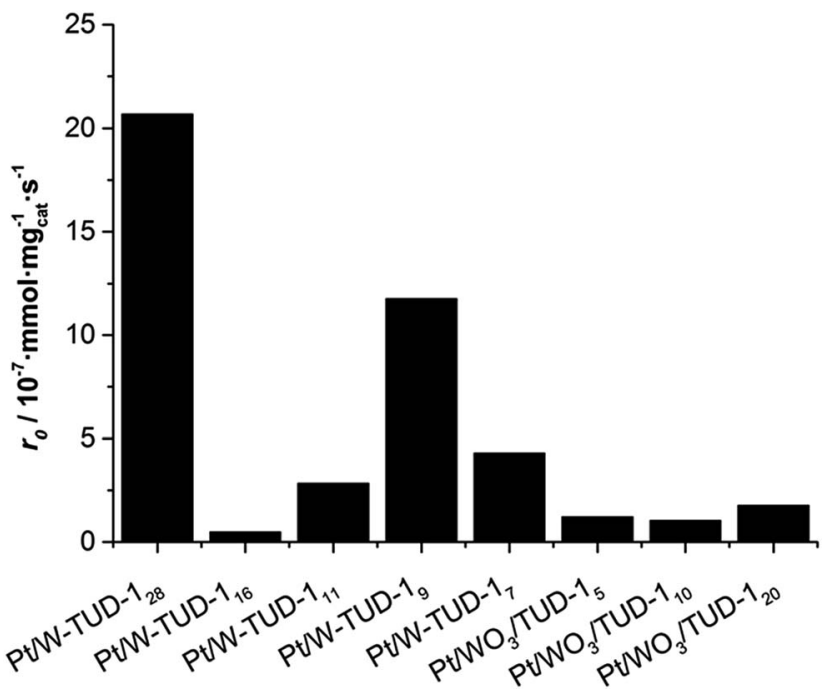

Fig. 7 Initial hydrogenation rate $r_{0}$ of isopulegol over Pt/W-TUD-1 and $\mathrm{Pt} / \mathrm{WO}_{3} / \mathrm{TUD}-1$ catalysts. Reaction conditions: $2.0 \mathrm{mmol}$ isopulegol, $4.0 \mathrm{~mL}$ toluene, $50 \mathrm{mg}$ catalyst, 20 bar $\mathrm{H}_{2}, 80^{\circ} \mathrm{C}, 800 \mathrm{rpm}$.

incipient wetness impregnation of the different catalysts must have led to a varying Pt dispersion, resulting in a wide range of hydrogenation activities.

Interestingly, no deoxygenated products are observed during the reaction, showing that under these reaction conditions the material is not acidic enough to remove the hydroxyl group that is present in both isopulegol and menthol.

Kinetic profile. The kinetic profile of Pt/W-TUD- $1_{11}$ shows that the conversion of isopulegol stabilizes around $40 \%$ (Fig. 8). This is attributed to catalyst deactivation, as other catalysts have shown higher conversions before (Fig. 7), ${ }^{31}$ so product inhibition is excluded as a cause. The deactivation starts in an early stage of the reaction and becomes progressively worse. This is visualized by the curve that predicts the menthol concentration in case the initial rate constant $k_{0}$ would be maintained throughout the reaction. Since the mass balance is around $95 \%$, some polymerization and coking could be possible deactivation mechanisms. Other possible deactivation mechanisms are sintering and poisoning. ${ }^{31}$

Poisoning is not expected by using these clean feeds, and product inhibition was not observed in previous studies of

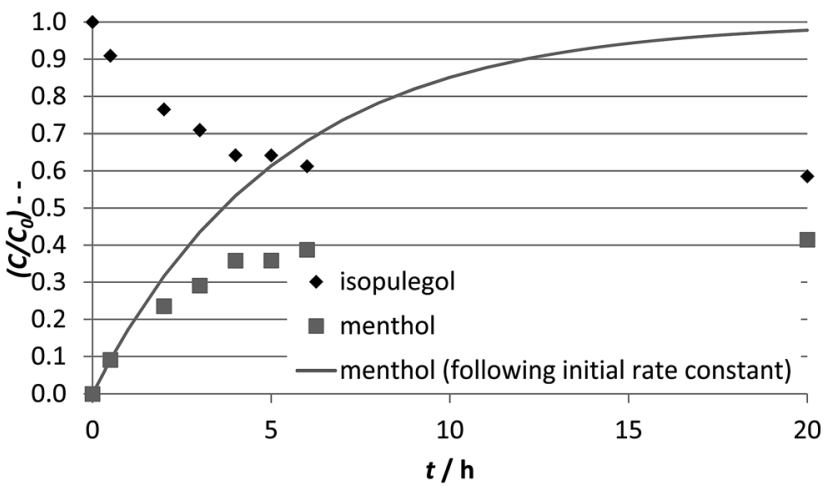

Fig. 8 Kinetic profiles of isopulegol hydrogenation using Pt/W-TUD$1_{11}$ as catalyst. Reaction conditions: $2.0 \mathrm{mmol}$ isopulegol, $4.0 \mathrm{~mL}$ toluene, $50 \mathrm{mg}$ catalyst, 20 bar $\mathrm{H}_{2}, 80^{\circ} \mathrm{C}$. The line indicates the menthol concentration development predicted based on the initial rate constant $k$.

isopulegol hydrogenation. ${ }^{3}$ Agglomeration of the Pt particles is observed by TEM after reaction, as can be seen in Fig. 9 .

Obviously, the observed catalyst deactivation has an effect on the accuracy of our assumption of first order rate dependence. However, this is still the best assumption that we can make.

Menthol synthesis. Hydrogenation of isopulegol only probed the hydrogenation activity of the bifunctional Pt/W-TUD-1 and $\mathrm{Pt} / \mathrm{WO}_{3} / \mathrm{TUD}-1$ catalysts. However, the acidic supports also allow for the Prins cyclisation of citronellal to isopulegol. This implies that menthol can be produced directly from citronellal, thereby fully utilizing the capabilities of these bifunctional catalysts (Table 3).

The highest menthol yield was achieved over Pt/W-TUD- $1_{11}$. Overall, 96\% citronellal could be converted into menthol by sequential operation. The remaining $4 \%$ was identified as $3,7-$ dimethyloctan-1-ol, resulting from the direct hydrogenation of citronellal. This clearly shows that the acidity of these materials does not lead to unwanted oxygen elimination.

The Prins cyclisation is performed under a nitrogen atmosphere in the first stage, as the hydrogenation of the carbonyl and alkene by the platinum catalyst would reduce the menthol selectivity significantly (converting citronellal into dimethyloctenol and dimethyloctanol (Tables 3 and 5), thereby preventing the formation of menthol). Overall, the Pt/W-TUD-1 

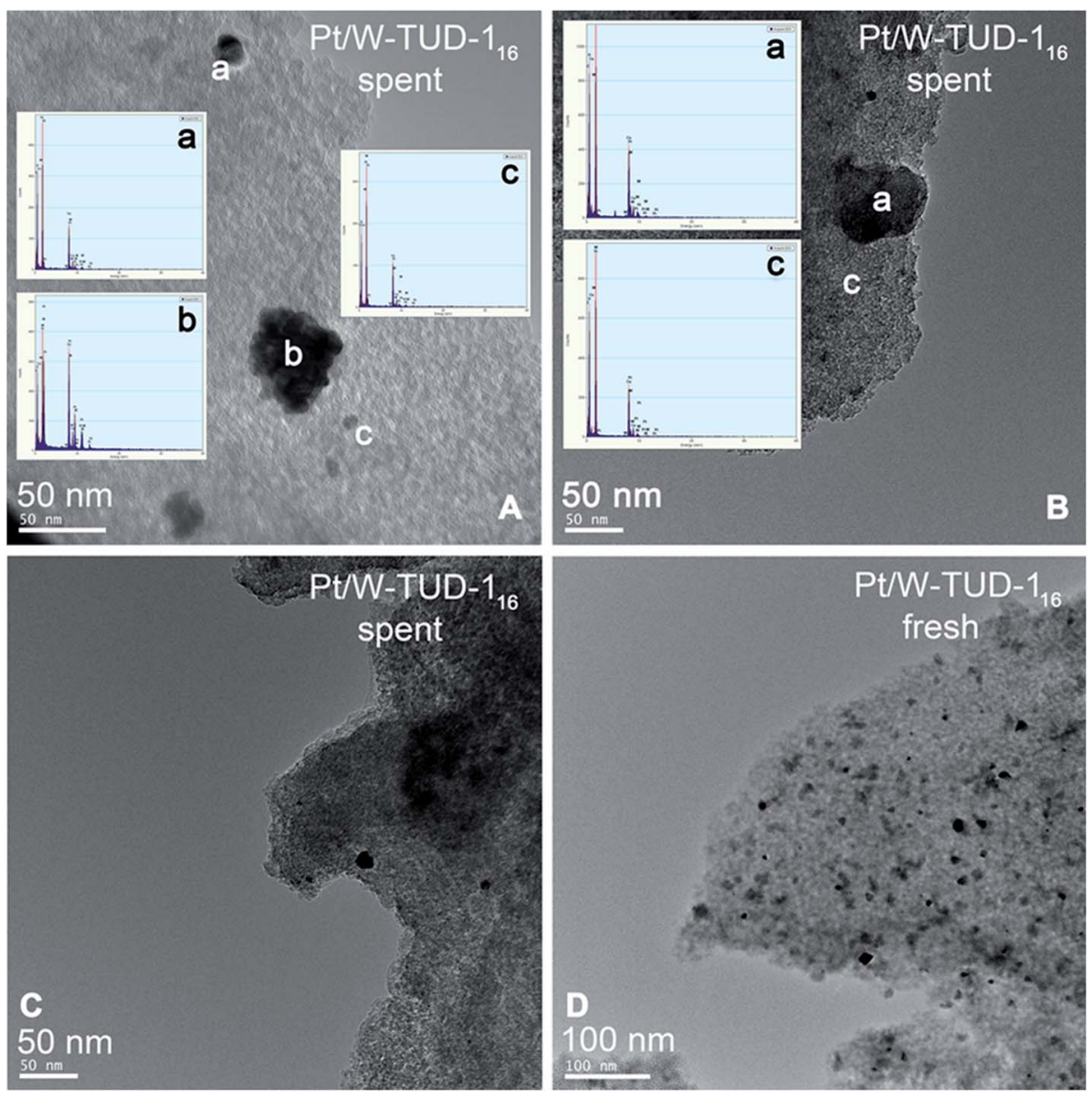

Fig. 9 TEM images and EDX analysis of spent (A, B and D) and fresh (D) Pt/W-TUD-1 $1_{16}$. WO 3 , Pt and background are labelled as a, b and $C$, respectively.

catalysts show a higher conversion of citronellal compared to the $\mathrm{Pt} / \mathrm{WO}_{3} / \mathrm{TUD}-1$ catalysts. In this series, the catalysts with a low tungsten loading (Pt/W-TUD-1 1 , 9 and 11 ) have a far higher $\mathrm{TOF}_{\mathrm{w}}$ than catalysts with a higher tungsten loading (Pt/W-TUD$1_{16}$ and 28 ). In fact, Pt/W-TUD- $1_{28}$ has a TOF $_{\mathrm{w}}$ that is comparable to the $\mathrm{TOF}_{\mathrm{w}}$ of the Pt/WO$/ \mathrm{WO}_{3} / \mathrm{TU}-1$ catalysts. The Pt/WO$/ \mathrm{TUD}-1$ catalysts show an increasing $\mathrm{TOF}_{\mathrm{w}}$ with decreasing tungsten loading. This is in agreement with earlier work with the W-TUD1 and $\mathrm{WO}_{3}$ /TUD-1 materials without Pt and is the result of the better dispersion of tungsten (Table 4). ${ }^{25}$ The highest TOF $_{\mathrm{w}}$ was observed for the Pt/W-TUD- $1_{11}$ catalyst, because this material contains an optimal amount of small $\mathrm{WO}_{3}$ particles (Table 1), without forming large, relatively non-acidic, $\mathrm{WO}_{3}$ particles. It exhibits the highest number of acid sites per tungsten (Table 4).

The surface coverage of tungsten on an alumina support was recently reported by García-Fernández et al. ${ }^{32}$ They evaluated the tungsten surface density $\left(\rho_{\mathrm{W}}\right.$, expressed in $\mathrm{W}$ atoms per $\left.\mathrm{nm}^{2}\right)$ according to the Kerkhof-Moulijn model. ${ }^{33}$ It was found that this model was valid for a tungsten loading up to $9 \mathrm{wt} \%$. At higher tungsten loadings the tungsten starts forming threedimensional clusters. This is somewhat in agreement with our observation that at higher $\mathrm{WO}_{3}$-loadings our catalysts are becoming less acidic per tungsten atom (Table 4). Obviously, the $\mathrm{WO}_{3}$ surface density $\left(\rho_{\mathrm{WO}_{3}}\right.$, expressed in $\mathrm{WO}_{3}$ molecules per $\mathrm{nm}^{2}$ ) at which three-dimensional clusters are formed is different for alumina and TUD-1 (a silica material). It is expected that these clusters start to form at lower $\rho_{\mathrm{WO}_{3}}$ because of the weaker interaction of a silica surface compared to an alumina surface. A strong indication for this is the decrease in surface area of the $\mathrm{WO}_{3} / \mathrm{TUD}-1$ and $\mathrm{Pt} / \mathrm{WO}_{3} / \mathrm{TUD}-1$ materials and W/TUD- $1_{28}$ and Pt/W-TUD- $1_{28}$ (Table 1 ).

After $5 \mathrm{~h}$ the second stage, the hydrogenation of isopulegol to menthol, was started by replacing the nitrogen atmosphere by the reducing hydrogen atmosphere. From this point on, the Prins cyclisation and hydrogenation proceed simultaneously. After $21 \mathrm{~h}$, the citronellal is completely converted over the Pt/WTUD-1 catalysts (except for Pt/W-TUD- $1_{16}$ ) into menthol 3 and dimethyloctanol 5. When Pt/W-TUD- $1_{16}$ was used, some isopulegol and 4 remained. This illustrates that hydrogenation over this catalyst is not so efficient, as was also shown for the neat hydrogenation (Table 2). Isopulegol and $\mathbf{4}$ are also observed when the $\mathrm{Pt} / \mathrm{WO}_{3} / \mathrm{TUD}-1$ catalyst samples were used, which is in agreement with the low $\mathrm{TOF}_{\mathrm{Pt}}$ for these catalysts that were determined for the hydrogenation (Table 2).

The $\mathrm{TOF}_{\mathrm{Pt}}$ 's for the isopulegol conversion experiment (Table 2) are lower than the $\mathrm{TOF}_{\mathrm{Pt}}$ 's were observed during the menthol synthesis experiment (Table 3). It was assumed that the $\mathrm{PtO}_{x}$ on the catalyst would readily reduce to the active metallic Pt under 
Table 3 Menthol synthesis in two stages. Stage 1 Prins cyclisation for $5 \mathrm{~h}$, stage 2 consecutive hydrogenation for $16 \mathrm{~h}^{a}$

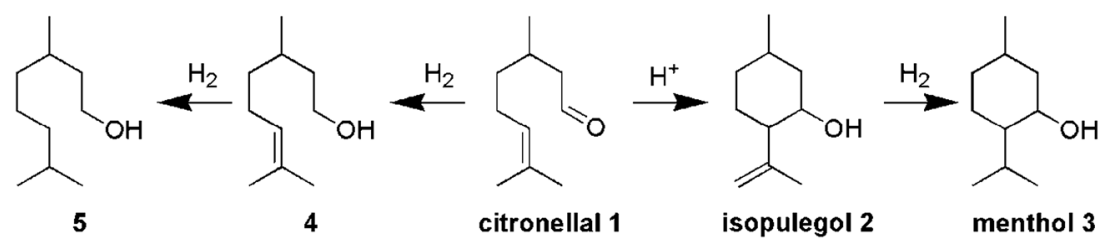

\begin{tabular}{|c|c|c|c|c|c|c|c|c|c|c|}
\hline \multirow[b]{3}{*}{ Catalyst } & \multirow{3}{*}{$\begin{array}{l}\text { Stage } 1 \\
\frac{\text { Yield }(\%) t=5 \mathrm{~h}}{2}\end{array}$} & \multicolumn{5}{|c|}{ Stage $1+$ stage 2} & \multicolumn{2}{|c|}{5 h Prins cyclisation } & \multicolumn{2}{|c|}{$16 \mathrm{~h}$ hydrogenation } \\
\hline & & \multicolumn{5}{|c|}{ Yield (\%) $t=21 \mathrm{~h}$} & \multirow{2}{*}{$\begin{array}{l}k^{b} \\
\left(\mu \mathrm{L} \mathrm{g}_{\mathrm{cat}}{ }^{-1} \mathrm{~s}^{-1}\right)\end{array}$} & \multirow{2}{*}{$\begin{array}{l}\mathrm{TOF}_{\mathrm{w}}{ }^{c} \\
\left(\mathrm{mmol} \mathrm{mol}_{\mathrm{W}}{ }^{-1} \mathrm{~s}^{-1}\right)\end{array}$} & \multirow{2}{*}{$\begin{array}{l}k^{d} \\
\left(\mu \mathrm{L} \mathrm{mg} \mathrm{cat}^{-1} \mathrm{~s}^{-1}\right)\end{array}$} & \multirow{2}{*}{$\begin{array}{l}\mathrm{TOF}_{\mathrm{Pt}}{ }^{e} \\
\left(\mathrm{mmol} \mathrm{mol}_{\mathrm{Pt}}{ }^{-1} \mathrm{~s}^{-1}\right)\end{array}$} \\
\hline & & 1 & 2 & 3 & 5 & 4 & & & & \\
\hline Pt/W-TUD-1 28 & 85.2 & 0 & 0 & 83.3 & 16.7 & 0 & 8.4 & 3.0 & 5.3 & 38.6 \\
\hline Pt/W-TUD-1 16 & 90.6 & 0 & 23.2 & 73.8 & 2.0 & 1.0 & 10.1 & 7.1 & 2.2 & 22.9 \\
\hline Pt/W-TUD-1 11 & 99.5 & 0 & 0 & 96.4 & 3.6 & 0 & 22.8 & 22.6 & 4.6 & 65.2 \\
\hline Pt/W-TUD-19 & 93.6 & 0 & 0 & 90.9 & 9.1 & 0 & 12.0 & 14.3 & 4.9 & 59.3 \\
\hline Pt/W-TUD-1 7 & 93.4 & 0 & 0 & 91.3 & 8.7 & 0 & 11.5 & 17.0 & 5.0 & 77.2 \\
\hline $\mathrm{Pt} / \mathrm{WO}_{3} / \mathrm{TUD} \mathrm{1}_{5}$ & 30.6 & 30.8 & 19.2 & 22.0 & 20.9 & 7.2 & 1.6 & 3.5 & $0.6^{f}$ & $4.8^{g}$ \\
\hline $\mathrm{Pt} / \mathrm{WO}_{3} / \mathrm{TUD}-1_{10}$ & 24.5 & 24.3 & 20.2 & 12.8 & 21.0 & 21.7 & 1.3 & 1.7 & $0.8^{f}$ & $5.6^{g}$ \\
\hline $\mathrm{Pt} / \mathrm{WO}_{3} / \mathrm{TUD}-1_{20}$ & 24.0 & 23.7 & 16.2 & 14.9 & 36.4 & 8.7 & 1.2 & 0.8 & $1.0^{f}$ & $7.6^{g}$ \\
\hline
\end{tabular}

${ }^{a}$ Reaction conditions Prins cyclisation: $2.0 \mathrm{mmol}$ citronellal, $4.0 \mathrm{~mL}$ toluene, $50 \mathrm{mg}$ catalyst, $80{ }^{\circ} \mathrm{C}, 20$ bar $\mathrm{N}_{2}, 5$ h; reaction conditions hydrogenation: reaction mixture (including catalyst) of Prins cyclisation is used, $80^{\circ} \mathrm{C}, 20$ bar $\mathrm{H}_{2}, 16 \mathrm{~h} .{ }^{b}$ Prins cyclisation rate constant $k$ is calculated from citronellal conversion after $5 \mathrm{~h}$ by assuming a first order in citronellal concentration. ${ }^{c}$ Prins cyclisation $\mathrm{TOF}_{\mathrm{w}}$ is calculated from the initial rate $r_{0}$, and accounts for the amount of $\mathrm{W}$ in the catalyst, defined as mol converted citronellal per mol W per s. ${ }^{d}$ Isopulegol hydrogenation rate constant $k$ is calculated assuming a first order in isopulegol concentration, and assuming no additional isopulegol is formed during hydrogenation $(t>5 \mathrm{~h})$ (therefore rate constants for Pt/ $\mathrm{WO}_{3} / \mathrm{TUD}-1$ catalysts cannot be calculated). ${ }^{e}$ Isopulegol hydrogenation TOF $\mathrm{pt}_{\mathrm{pt}}$ is calculated from the initial rate $r_{0}$, and accounts for the amount of $\mathrm{Pt}$ in the catalyst, defined as mol converted isopulegol per mol Pt per s. ${ }^{f}$ Citronellal double bond hydrogenation rate constant $k$ is calculated for the Pt/ $\mathrm{WO}_{3} / \mathrm{TUD}-1$ catalysts, assuming a first order in citronellal double bond concentration, and assuming no additional Prins cyclisation occurs during hydrogenation. ${ }^{g}$ Citronellal double bond hydrogenation $\mathrm{TOF}_{\mathrm{Pt}}$ is calculated from the initial rate $r_{0}$, and accounts for the amount of Pt in the catalyst, defined as mol converted double bond per mol Pt per s.

Table $4 \quad \mathrm{NH}_{3}$-TPD acidity ${ }^{23}$

\begin{tabular}{|c|c|c|c|}
\hline Catalyst & $\begin{array}{l}\text { Total acidity }{ }^{a} \\
\left(\mathrm{mmol} \mathrm{g}_{\mathrm{cat}}{ }^{-1}\right)\end{array}$ & $\begin{array}{l}\text { Acidity } / \mathrm{W}^{b} \\
\left(\mathrm{~mol}_{\mathrm{H}^{+}} \mathrm{mol}_{\mathrm{W}}{ }^{-1}\right)\end{array}$ & $\begin{array}{l}\rho_{\mathrm{WO}_{3}} \\
\left(\mathrm{WO}_{3} \text { units } \mathrm{nm}^{-2}\right)\end{array}$ \\
\hline TUD-1 & 0.02 & n.a. & n.a. \\
\hline $\mathrm{WO}_{3}$ (ref. 34) & 0.0 & n.a. & n.a. \\
\hline $\mathrm{WO}_{3} / \mathrm{TUD} \mathrm{1}_{10}$ & 0.34 & 0.90 & 0.38 \\
\hline $\mathrm{WO}_{3} / \mathrm{TUD} \mathbf{1}_{20}$ & 0.45 & 0.57 & 0.88 \\
\hline W-TUD- $1_{7}$ & 0.38 & 1.09 & 0.29 \\
\hline W-TUD-1, & 0.52 & 1.26 & 0.39 \\
\hline W-TUD- $1_{11}$ & 0.78 & 1.47 & 0.45 \\
\hline W-TUD- $1_{16}$ & 0.99 & 1.35 & 0.70 \\
\hline W-TUD- $1_{28}$ & 0.47 & 0.35 & 1.92 \\
\hline
\end{tabular}

${ }^{a}$ Total catalyst acidity determined over a temperature range of $100-$ $600{ }^{\circ} \mathrm{C} .{ }^{b}$ Acidity derived from $\mathrm{WO}_{3}$ can be considered as Brønsted acid. $^{35}$

20 bar of pure hydrogen at reaction temperature but it seems that this was not the case. The 5 hours under nitrogen atmosphere might have pre-reduced the $\mathrm{PtO}_{x}$ on the catalyst, resulting in a higher activity.

In this experiment, a direct comparison of the hydrogenation efficiency of the eight acidic hydrogenation catalysts is difficult, as the different catalysts are subjected to different substrate concentrations, which is a direct result from the preceding Prins cyclisation.
The five Pt/W-TUD-1 catalysts can be compared, as the initial Prins cyclisation over these catalysts was almost complete, which resulted in comparable starting concentrations of isopulegol. Using a first order rate approximation an isopulegol hydrogenation rate constant can then be derived for these catalysts. This is used to calculate initial rates $r_{0}$ and TOF $_{\mathrm{Pt}}$. This shows that the $\mathrm{Pt} /$ W-TUD-1 catalysts have TOF $_{\mathrm{Pt}}$ values that are in the same order of magnitude $\left(2.3-7.7 \times 10^{-2} \mathrm{~mol}\right.$ per molPt per s) and also comparable to those in Table 2, which is to be expected when conversions are close to $100 \%$ and $\mathrm{Pt}$ concentrations in the different experiments are comparable.

However, this approach cannot be applied to analysis of the Pt/ $\mathrm{WO}_{3} / \mathrm{TUD}-1$ samples, as after the initial Prins cyclisation stage only $25-30 \%$ isopulegol was produced. In order to be able to compare the hydrogenation activity under these conditions, the concentration of double bonds in citronellal that is left after Prins cyclisation was defined. A double bond hydrogenation (both carbon-carbon and carbon-oxygen double bonds) rate constant $k$ was then calculated, assuming a first order rate approximation and similar reactivity. From these $k$ values, initial rates $r_{0}$ were calculated. These were normalized for Pt content to get $\mathrm{TOF}_{\mathrm{Pt}}$ values.

Recycling experiments. The catalysts were separated from the reaction mixture and subjected to another round of menthol synthesis to investigate their recyclability (Table 5). The initial 


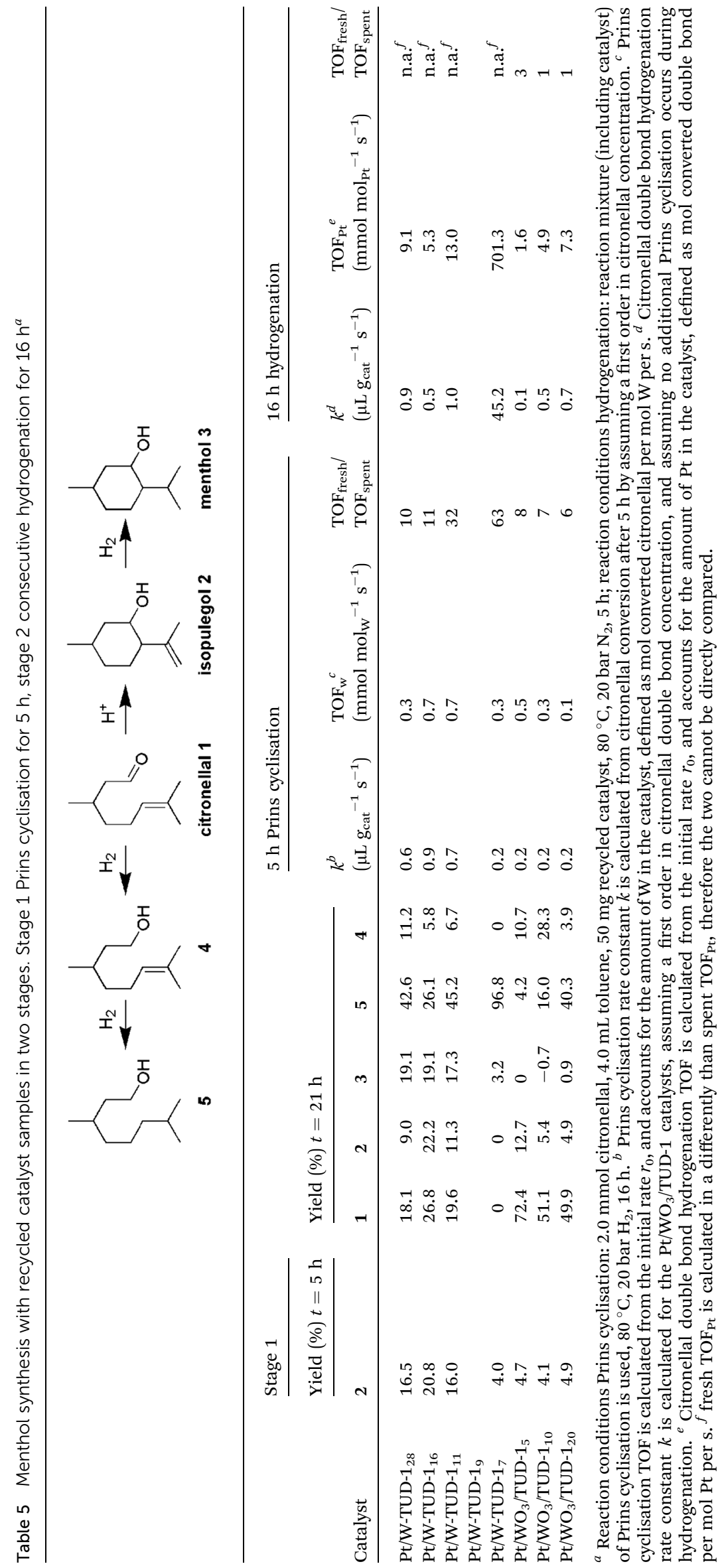


Prins cyclisation clearly shows that the solid acid's activity is greatly reduced after one cycle. Obviously, a deactivation mechanism is at play for all catalysts. TEM analysis shows that agglomeration of $\mathrm{WO}_{3}$ particles occurred, resulting in larger, less active particles (Fig. 9). This was previously shown for the materials without $\mathrm{Pt}^{25}$

The recycled $\mathrm{Pt} / \mathrm{WO}_{3} / \mathrm{TUD}-1$ catalysts all show a one order of magnitude lower Prins cyclisation activity, independent of the tungsten loading. This is likely due to relatively large $\mathrm{WO}_{3}$ particles of similar size that are present in these catalysts that agglomerate at comparable rates. The recycled $\mathrm{Pt} / \mathrm{WO}_{3} / \mathrm{TUD}-1$ catalysts are again outperformed by the Pt/W-TUD-1 catalysts in this acid catalysed citronellal conversion. However, the $\mathrm{TOF}_{\mathrm{w}}{ }^{\text {'s }} \mathrm{s}$ of the two types of recycled catalyst are now of the same order of magnitude. Interestingly, the recycled Pt/W-TUD-1 catalysts with higher tungsten loadings (Pt/W-TUD-1 $1_{28}, 16$ and 11) now exhibit higher citronellal conversion than the catalyst with the lowest tungsten loading, which in this recycle experiment only shows minimal Prins cyclisation activity. The $\mathrm{TOF}_{\mathrm{w}}$ of the Pt/W-TUD- $1_{11}$ and 7 catalysts had decreased by a factor 33 and 63 , respectively, while the $\mathrm{TOF}_{\mathrm{w}}$ of the Pt/W-TUD- $\mathbf{1}_{28}$ and 16 only decreased by a factor 10 . This indicates that the small $\mathrm{WO}_{3}$ particles that were present on the original Pt/W-TUD- $1_{11}$ and 7 materials are prone to agglomeration, resulting in decreased catalytic activity. So, the decrease in Prins cyclisation activity is attributed to the agglomeration of the finely dispersed small $\mathrm{WO}_{3}$ particles. The agglomeration of small $\mathrm{WO}_{3}$ particles has a relatively larger effect on the acidity of the material, and hence the acidic activity of the catalyst, than agglomeration of larger $\mathrm{WO}_{3}$ particles.

The reduced acidic activity of the bifunctional catalysts impacts the overall menthol synthesis. As less isopulegol is formed, less menthol is produced. The citronellal that is still present after $5 \mathrm{~h}$ of Prins cyclisation can continue to be converted into isopulegol during the hydrogenation stage. This is observed for Pt/W-TUD- $1_{28}, 16$ and 11 and Pt/WO $/$ TUD- $1_{5}$. However, larger amounts of $\mathbf{4}$ and $\mathbf{5}$ are now observed as citronellal can also be hydrogenated before it is converted into isopulegol. This shows that all eight catalysts still exhibit hydrogenation activity.

As the hydrogenation $\mathrm{TOF}_{\mathrm{Pt}}$ with regards to menthol cannot be calculated for these recycled catalysts, it is difficult to compare the hydrogenation activities of the Pt/W-TUD-1 catalysts. However, due to the lack of acid activity for these recycled catalysts, the hydrogenation activity can still be evaluated using the same approach that was used to determine the $\mathrm{TOF}_{\mathrm{Pt}}$ in the fresh $\mathrm{Pt} / \mathrm{WO}_{3} / \mathrm{TUD}-1$ samples in Table 3 . The concentration of double bonds in citronellal that is still present after Prins cyclisation was defined and a first order rate approximation was assumed with respect to the hydrogenated products $\mathbf{4}$ and $\mathbf{5}$ to calculate a hydrogenation rate constant $k$ for the different catalysts. Initial rates $r_{0}$ were calculated from these rate constants and normalizing them on Pt content provides $\mathrm{TOF}_{\mathrm{Pt}}$ values.

These $\mathrm{TOF}_{\mathrm{Pt}}$ values can only be compared to the $\mathrm{TOF}_{\mathrm{Pt}}$ values of the fresh $\mathrm{Pt} / \mathrm{WO}_{3} / \mathrm{TUD}-1$ catalysts, as they are calculated in the same way. This shows that the hydrogenation $\mathrm{TOF}_{\mathrm{Pt}}$ for the $\mathrm{Pt} / \mathrm{WO}_{3} / \mathrm{TUD}-1$ is maintained after the recycle for $\mathrm{Pt} / \mathrm{WO}_{3} / \mathrm{TUD}$ $1_{20}$ and $\mathrm{Pt} / \mathrm{WO}_{3} / \mathrm{TUD}-1_{10}$, while the $\mathrm{TOF}_{\mathrm{w}}$ for $\mathrm{Pt} / \mathrm{WO}_{3} / \mathrm{TUD}-\mathbf{1}_{5}$ has slightly decreased, but still has the same order of magnitude.
On the other hand, the $\mathrm{TOF}_{\mathrm{w}}$ 's of Pt/W-TUD-1 128,16 and 11 have decreased by a factor of 5 . This is in agreement with Fig. 9A, where an increase in Pt particle size can be seen in comparison with the fresh catalyst.

Initially, the higher $\mathrm{WO}_{3}$ dispersion on the fresh Pt/W-TUD-1 catalysts compared to the fresh $\mathrm{Pt} / \mathrm{WO}_{3} / \mathrm{TUD}-1$ catalysts resulted in increased isopulegol formation and $\mathrm{TOF}_{\mathrm{w}}$. However, catalysts that contain small $\mathrm{WO}_{3}$ particles, which are responsible for initial high activity (Pt/W-TUD-1), are more affected by particle agglomeration than the bulk $\mathrm{WO}_{3}$ phase that is present in the $\mathrm{Pt} / \mathrm{WO}_{3} / \mathrm{TUD}-1$ catalysts. As a result, the $\mathrm{TOF}_{\mathrm{w}}$ for catalysts that contained these small $\mathrm{WO}_{3}$ particles decreased more than the catalysts that contained more bulk $\mathrm{WO}_{3}$.

The hydrogenation TOF $_{\mathrm{Pt}}$ is higher for the catalysts containing finely dispersed $\mathrm{WO}_{3}$ particles, i.e. Pt/W-TUD-1, than for the bulk $\mathrm{WO}_{3}$ containing $\mathrm{Pt} / \mathrm{WO}_{3} / \mathrm{TUD}-1$ catalysts. However, recycling of the catalysts showed that the hydrogenation activity only decreased for the spent Pt/W-TUD-1 catalysts. This indicates that the Pt on the Pt/W-TUD-1 catalysts differs from the Pt on the Pt/ $/ \mathrm{WO}_{3} /$ TUD-1 samples and that the Pt on the Pt/ $/ \mathrm{WO}_{3} /$ TUD- 1 is relatively stable, but less active.

As a hypothesis, this could be due to the Pt being located on the finely dispersed $\mathrm{WO}_{3}$, resulting in a more active Pt phase, but one that is deactivated more readily upon agglomeration of the small $\mathrm{WO}_{3}$ particles during reaction..$^{32,36}$

\section{Conclusions}

A series of bifunctional heterogeneous catalysts was prepared through platinum impregnation of two different types of acidic tungsten oxide containing supports with different tungsten oxide loadings. A kinetic analysis was performed to compare the catalytic activities of the synthesized catalysts. These catalysts have proven to be effective in the acid catalyzed Prins cyclisation of citronellal and the subsequent hydrogenation of isopulegol into menthol. The unwanted acid catalyzed dehydroxylation was not observed for any of these catalysts.

Pt/W-TUD-1 materials are more active in the Prins cyclisation of citronellal than their $\mathrm{Pt} / \mathrm{WO}_{3} / \mathrm{TUD}-1$ counterparts. A good dispersion of $\mathrm{WO}_{3}$ is critical for high acidity and introducing the tungsten during the TUD-1 synthesis results in a higher $\mathrm{WO}_{3}$ dispersion than after impregnation of TUD-1. Unfortunately, these small $\mathrm{WO}_{3}$ particles are more sensitive to agglomeration during the reaction and the spent Pt/W-TUD-1 catalysts have $\mathrm{TOF}_{\mathrm{w}}$ 's that are more resembling the activity of the less active bulk $\mathrm{WO}_{3}$. The highest activity was observed for the fresh Pt/W-TUD- $1_{11}$ catalyst, attributed to an optimum between dispersion and $\mathrm{WO}_{3}$ loading, i.e. higher $\mathrm{WO}_{3}$ loading resulted in a lower dispersion, whereas a lower loading implies less available active tungsten.

The Pt/W-TUD-1 materials are also more active hydrogenation catalysts than the $\mathrm{Pt} / \mathrm{WO}_{3} / \mathrm{TUD}-1$ materials. No correlation between tungsten loading and hydrogenation activity exists, but there is a correlation between hydrogenation activity and the presence of small $\mathrm{WO}_{3}$ particles. The hydrogenation activity of the catalysts remains after recycling for the Pt/WO $/$ TUD- 1 catalysts, while it decreased for the Pt/W-TUD-1 catalysts. This 
suggests that initially the $\mathrm{Pt}$ is present on the small $\mathrm{WO}_{3}$ particles in the Pt/W-TUD-1 catalysts, but this activity is lost during reaction due to agglomeration of the small $\mathrm{WO}_{3}$ particles.

\section{Acknowledgements}

J. t. D. gratefully acknowledges financial support from NWO ASPECT (053.62.020).

\section{Notes and references}

1 E. J. Lenardao, G. V. Botteselle, F. de Azambuja, G. Perin and R. G. Jacob, Tetrahedron, 2007, 63, 6671.

2 C. Barrales Cortés, V. Tamayo Galván, S. Santiago Pedro and T. Viveros García, Catal. Today, 2011, 172, 21.

3 Y. Nie, W. Niah, S. Jaenicke and G.-K. Chuah, J. Catal., 2007, 248, 1 .

4 K. A. da Silvia Rocha, P. A. Robles-Dutenhefner, E. M. B. Sousa, E. F. Kozhevnikova, I. V. Kozhevnikov and I. V. Gusevskaya, Appl. Catal., A, 2007, 317, 171.

5 J. Plößer, M. Lucas and P. Claus, J. Catal., 2014, 320, 189.

6 A. Negoi, S. Wuttke, E. Kemnitz, D. Macovei, V. I. Parvulescu, C. M. Teodorescu and S. M. Coman, Angew. Chem., Int. Ed., 2010, 49, 8134.

7 F. G. Cirujano, F. X. Llabrés I Xamena and A. Corma, Dalton Trans., 2012, 41, 4249.

8 G.-K. Chuah, S. H. Liu, S. Jaenicke and L. J. Harrison, J. Catal., 2001, 200, 352.

9 Z. Yongzhong, N. Yuntong, S. Jaenicke and G.-K. Chuah, J. Catal., 2005, 229, 404.

10 M. Vandichel, F. Vermoortele, S. Cottenie, D. E. De Vos, M. Waroquier and V. Van Speybroeck, J. Catal., 2013, 305, 118.

11 P. Mäki-Arvela, N. Kumar, V. Nieminen, R. Sjöholm, T. Salmi and D. Y. Murzin, J. Catal., 2004, 225, 155.

12 M. Fuentes, J. Magraner, C. de las Pozas and R. RoqueMalherbe, Appl. Catal., A, 1989, 47, 367.

13 S. Telalović, A. Ramanathan, J. F. Ng, R. Maheswari, C. Kwakernaak, F. Soulimani, H. C. Brouwer, G. K. Chuah, B. M. Weckhuysen and U. Hanefeld, Chem.-Eur. J., 2011, 17, 2077.

14 A. Ranoux, K. Djanashvili, I. W. C. E. Arends and U. Hanefeld, RSC Adv., 2013, 3, 21524.

15 R. Nieguth, J. ten Dam, A. Petrenz, A. Ramanathan, U. Hanefeld and M. B. Ansorge-Schumacher, RSC Adv., 2014, 4, 45495.

16 Y. Chen, Z. Guo, T. Chen and Y. Yang, J. Catal., 2010, 275, 11. 17 M. Ferrari, B. Delmon and P. Grange, Carbon, 2002, 40, 471.
18 D. Liu, X.-Y. Quek, S. Hu, L. Li, H. M. Lim and Y. Yang, Catal. Today, 2009, 147, S51.

19 L. Tang, G. Luo, M. Zhy, L. Kang and B. Dai, J. Ind. Eng. Chem., 2013, 19, 620.

20 S. K. Wilkinson, I. McManus, H. Daly, J. M. Thompson, C. Hardacre, N. Sedaie Bonab, J. ten Dam, M. J. H. Simmons, C. D'Agostino, J. McGregor, L. F. Gladden and E. H. Stitt, J. Catal., 2015, 330, 362.

21 I. McManus, H. Daly, J. M. Thompson, E. Connor, C. Hardacre, S. K. Wilkinson, N. Sedaie Bonab, J. ten Dam, M. J. H. Simmons, E. H. Stitt, C. D'Agostino, J. McGregor, L. F. Gladden and J. J. Delgado, J. Catal., 2015, 330, 344.

22 A. Ramanathan, M. C. C. Villalobos, C. Kwakernaak, S. Telalović and U. Hanefeld, Chem.-Eur. J., 2008, 14, 961.

23 T. Yang, H. Ling, J.-F. Lamonier, M. Jaroniec, J. Huang, M. J. Monteiro and J. Liu, NPG Asia Mater., 2016, 8, e240.

24 H. Ataee-Esfahani, J. Liu, M. Hu, N. Miyamoto, S. Tominaka, K. C. W. Wu and Y. Yamauchi, Small, 2013, 9, 1047.

25 J. ten Dam, D. Badloe, A. Ramanatan, K. Djanashvili, F. Kapteijn and U. Hanefeld, Appl. Catal., A, 2013, 468, 150. 26 T. Heikkilä, J. Salonen, J. Tuura, M. S. Hamdy, G. Mul, N. Kumar, T. Salmi, D. Y. Murzin, L. Laitinen, A. M. Kaukonen, J. Hirvonen and V. P. Lehto, Int. J. Pharm., 2007, 331, 133.

27 M. F. de Lange, T. J. H. Vlugt, J. Gascon and F. Kapteijn, Microporous Mesoporous Mater., 2014, 200, 199.

28 K. S. W. Sing, D. H. Everett, R. A. W. Haul, L. Moscou, R. A. Pierotti, J. Rouquérol and T. Siemieniewska, Pure Appl. Chem., 1985, 57, 603.

29 J. C. Groen and J. Perez-Ramirez, Appl. Catal., A, 2005, 268, 121.

30 NIST Standard Reference Database 20, http://srdata.nist.gov/ xps.

31 J. A. Moulijn, A. E. van Diepen and F. Kapteijn, Appl. Catal., A, 2001, 212, 3 .

32 S. García-Fernández, I. Gandarias, J. Requies, M. B. Güemez, S. Bennici, A. Auroux and P. L. Arias, J. Catal., 2015, 323, 65.

33 F. P. J. M. Kerkhof and J. A. Moulijn, J. Phys. Chem., 1979, 83, 1612.

34 D. Hua, S.-L. Chen, G. Yuan, Y. Wang, Q. Zhao, X. Wang and B. Fu, Microporous Mesoporous Mater., 2011, 143, 320.

35 D. G. Barton, S. L. Soled and E. Iglesia, Top. Catal., 1998, 6, 87.

36 E. V. Ramos-Fernandez, C. J. M. Pieters, B. J. van der Linden, J. Juan Alcaniz, P. Serra Crespo, M. W. G. M. Verhoeven, J. W. Niemantsverdriet, J. Gascon and F. Kapteijn, J. Catal., 2012, 289, 42. 